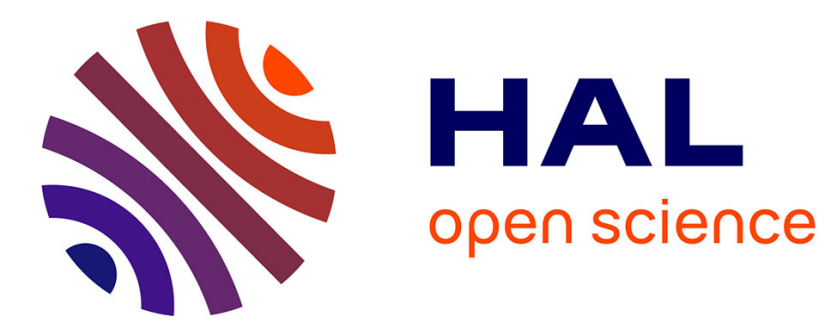

\title{
Lipid Droplets Breakdown: Adipose Triglyceride Lipase Leads the Way
}

Pierre Santucci, Stéphane Canaan

\section{To cite this version:}

Pierre Santucci, Stéphane Canaan. Lipid Droplets Breakdown: Adipose Triglyceride Lipase Leads the Way. Current Protein and Peptide Science, 2018, 19 (11), pp.1131-1133. 10.2174/1389203719666180809143000 . hal-01860671

\section{HAL Id: hal-01860671 \\ https://hal-amu.archives-ouvertes.fr/hal-01860671}

Submitted on 27 Aug 2018

HAL is a multi-disciplinary open access archive for the deposit and dissemination of scientific research documents, whether they are published or not. The documents may come from teaching and research institutions in France or abroad, or from public or private research centers.
L'archive ouverte pluridisciplinaire HAL, est destinée au dépôt et à la diffusion de documents scientifiques de niveau recherche, publiés ou non, émanant des établissements d'enseignement et de recherche français ou étrangers, des laboratoires publics ou privés. 
Lipid Droplets Breakdown: Adipose Triglyceride Lipase Leads the Way

Pierre Santucci and Stéphane Canaan*

Aix-Marseille Université, CNRS, LISM, IMM FR3479, Marseille, France.

*Corresponding author, email: stephane.canaan@imm.cnrs.fr, phone 33491164093 


\section{Previously in Current Protein \& Peptide Science, Cerk et al. (2018) presented an updated review} of concepts and knowledge regarding structure, function and regulatory mechanism of the adipose triglyceride lipase (ATGL), one of the key-enzyme required for intracellular lipolysis.

Until recently, lipid droplets (LDs) were just considered as neutral lipid storage sites, thus providing energy through lipolysis and $\beta$-oxidation pathway when required during stressful conditions [1]. Nowadays, it's clearly established that LDs are well-organized and extremely dynamic cellular organelles, conserved in eubacteria, fungi, plants and animals, where they are essential for lipid homeostasis and energy maintenance[2]. Alteration of these two critical physiological processes can lead to important metabolic disorders [3]. The "conventional snapshot representation" of LDs remains a suitable model for defining their general composition which is based on a central organic core of neutral lipids (mainly triacylglycerol (TAG) and sterol esters) surrounded by a monolayer of phospholipids [4], associated with a wide range of structural [5], enzymatic [6] and membranetrafficking proteins [7]. However, we also know that proteins and lipid species of such structures can be extremely diversified depending on the different cell types or metabolic status. Interestingly, LDs anabolism and catabolism are well-balanced and tightly controlled biological mechanisms involving a large number of actors at both transcriptional, translational and post-translational levels [8]. TAGcontaining LDs breakdown is achieved during extended starvation period or enhanced energy demand, and this phenomenon is mainly mediated by three distinct lipolytic enzymes (i.e. the adipose triglyceride lipase (ATGL), the hormone-sensitive lipase (HSL) and the monoglyceride lipase (MGL)) that act sequentially to finally generate free fatty acids (FFA) and glycerol molecules [8]. Since ATGL is catalyzing the first step of this essential lipolytic pathway, it's crucial to fully define physiological function(s) and structural properties of this protein but also to obtain further insights onto the regulatory mechanisms governing ATGL action towards LDs [9].

In a fascinating way, ATGL was discovered fourteen years ago by three independent groups at the same time [10-12]. Reports described that the protein was displaying a strong TAG-hydrolase activity in both in-vitro and ex-vivo experimental conditions [10-12]. Moreover, Atgl gene was highly 
expressed within adipose tissues, and to a lesser level in liver, spleen, kidney, heart and skeletal muscle $[10,12]$. To better understand the physiological role of this $54 \mathrm{kDa}$ protein in lipid homeostasis, an $\mathrm{Atgl}^{-/}$mutant mouse was generated, and study of this mouse permitted to obtained the first evidences that the ATGL protein is playing an essential role in TAG hydrolysis in-vivo [13]. Indeed, several phenotypes related to lipid metabolism disorder were easily observed within an Atgl null mutant such as increase in body weight, fat mass, fat accumulation in non-adipose tissues, and also a greater resistance to glucose and insulin. In addition, this deficiency rapidly triggered TAG accumulation within cardiac muscle thus leading to cardiac dysfunction and premature death $[9,13]$. All these findings suggested that a new essential component was involved in central lipid metabolism, and thus opening new perspectives to better control lipid metabolic disorder in patients.

These information prompted several teams to further investigate, during the last decade, the potential regulatory mechanisms involved in ATGL activity and to date, a large number of ATGL posttranslational modifications have been identified. In this context Cerk, Wechselberger and Oberer report in their recent paper published in Current Protein \& Peptide Science, 2018;19(2):221-233, an updated and nice overview of knowledge regarding ATGL function with special focus onto these post-translational regulatory mechanisms impacting its TAG-hydrolase activity during LDs breakdown [14].

Among the proteins involved in this regulation process, Plin1 (one of the five members of the perilipin family (Plin1-Plin5)) CGI-58, G0S2 and PEDF are probably the most important factors impacting ATGL activity [14]. Plin1 is mastering the switch from basal to stimulated lipolysis, and this is mediated by its C-terminal domain which sequesters the CGI-58 protein and so prevents the action of the ATGL [15]. Upon specific hormonal stimulation Plin1 is phosphorylated and releases the CGI-58 co-activator protein which binds to ATGL and leads to its translocation at the LDs surface [15]. Point mutations, insertions or deletions within the cgi-58 gene trigger a drastic neutral lipid storage disorder also called Chanarin-Dorfman syndrome thus emphasizing the role of CGI-58 protein in LDs degradation $[15,16]$. In addition to CGI-58, the PEDF protein is also known for interacting with ATGL and stimulating lipolysis in adipocytes [17]. In contrast to CGI-58 and PEDF which are 
activators, G0S2 protein is negatively regulating ATGL activity in both in-vitro and in-vivo conditions where overexpression leads to an almost identical phenotype than an $\mathrm{Atgl}^{-1-}$ mutant [18-20].

Another important part of their manuscript was dedicated to the inhibition of ATGL activity by either natural or synthetic small molecules [14]. One of the main inhibitory mechanism towards ATGL and also HSL is mediated by acyl-CoA availability within the cells [21, 22]. Indeed, an increase level of such molecules drastically impairs LDs-associated lipases activities and could directly contribute to the feedback inhibition of lipolysis. Finally, during high throughput screening of chemical compounds, one specific synthetic molecule has been identified as powerful inhibitor of ATGL. This compound named Atglistatin selectively inhibits the mouse ATGL activity at a micro/nanomolar range and drastically reduce TAG and FFA plasma level [23].

A large number of open questions needs to be further investigated regarding these dynamic interactions and new approaches a currently developed to better understand such mechanisms. For example, by generating translational fusions between the APEX2 protein and either the Plin2 or the ATGL protein, Bersuker et al., recently define with an high confidence a dynamic LD proteome in human cells [24]. By using this powerful proximity labelling strategy, they were able to identify new LDs-associated proteins but also to describe new potential interactions between structural, enzymatic and membrane-trafficking proteins [24]. LDs metabolism plays an important role in several diseases, such as obesity, atherosclerosis, metabolic syndrome, neurodegenerative diseases and mitochondrial disorders, which often lead to diabetes and cardiovascular complications. Altogether, these information summarized by Cerk et al., demonstrated that understanding the molecular mechanism of ATGL action and its regulation are crucial to further developed potent molecules for the treatment of such neutral lipid storage disorder. 


\section{References}

1. Farese, R.V., Jr. and T.C. Walther, Lipid droplets finally get a little R-E-S-P-E-C-T. Cell, 2009. 139(5): p. 855-60.

2. Murphy, D.J., The biogenesis and functions of lipid bodies in animals, plants and microorganisms. Prog Lipid Res, 2001. 40(5): p. 325-438.

3. Welte, M.A., Expanding roles for lipid droplets. Curr Biol, 2015. 25(11): p. R470-81.

4. Tauchi-Sato, K., et al., The surface of lipid droplets is a phospholipid monolayer with a unique Fatty Acid composition. J Biol Chem, 2002. 277(46): p. 44507-12.

5. Greenberg, A.S., et al., Perilipin, a major hormonally regulated adipocyte-specific phosphoprotein associated with the periphery of lipid storage droplets. J Biol Chem, 1991. 266(17): p. 11341-6.

6. Sztalryd, C., et al., Perilipin A is essential for the translocation of hormone-sensitive lipase during lipolytic activation. J Cell Biol, 2003. 161(6): p. 1093-103.

7. Liu, P., et al., Chinese hamster ovary K2 cell lipid droplets appear to be metabolic organelles involved in membrane traffic. J Biol Chem, 2004. 279(5): p. 3787-92.

8. Lass, A., et al., Lipolysis - a highly regulated multi-enzyme complex mediates the catabolism of cellular fat stores. Prog Lipid Res, 2011. 50(1): p. 14-27.

9. Zechner, R., et al., Adipose triglyceride lipase and the lipolytic catabolism of cellular fat stores. J Lipid Res, 2009. 50(1): p. 3-21.

10. Zimmermann, R., et al., Fat mobilization in adipose tissue is promoted by adipose triglyceride lipase. Science, 2004. 306(5700): p. 1383-6.

11. Jenkins, C.M., et al., Identification, cloning, expression, and purification of three novel human calcium-independent phospholipase A2 family members possessing triacylglycerol lipase and acylglycerol transacylase activities. J Biol Chem, 2004. 279(47): p. 48968-75.

12. Villena, J.A., et al., Desnutrin, an adipocyte gene encoding a novel patatin domaincontaining protein, is induced by fasting and glucocorticoids: ectopic expression of desnutrin increases triglyceride hydrolysis. J Biol Chem, 2004. 279(45): p. 47066-75.

13. Haemmerle, G., et al., Defective lipolysis and altered energy metabolism in mice lacking adipose triglyceride lipase. Science, 2006. 312(5774): p. 734-7.

14. Cerk, I.K., L. Wechselberger, and M. Oberer, Adipose Triglyceride Lipase Regulation: An Overview. Curr Protein Pept Sci, 2018. 19(2): p. 221-233.

15. Lass, A., et al., Adipose triglyceride lipase-mediated lipolysis of cellular fat stores is activated by CGI-58 and defective in Chanarin-Dorfman Syndrome. Cell Metab, 2006. 3(5): p. 309-19.

16. Lefevre, C., et al., Mutations in CGI-58, the gene encoding a new protein of the esterase/lipase/thioesterase subfamily, in Chanarin-Dorfman syndrome. Am J Hum Genet, 2001. 69(5): p. 1002-12.

17. Borg, M.L., et al., Pigment epithelium-derived factor regulates lipid metabolism via adipose triglyceride lipase. Diabetes, 2011. 60(5): p. 1458-66.

18. Yang, X., et al., The $G(0) / G(1)$ switch gene 2 regulates adipose lipolysis through association with adipose triglyceride lipase. Cell Metab, 2010. 11(3): p. 194-205.

19. Heckmann, B.L., et al., Defective adipose lipolysis and altered global energy metabolism in mice with adipose overexpression of the lipolytic inhibitor G0/G1 switch gene 2 (GOS2). J Biol Chem, 2014. 289(4): p. 1905-16.

20. Cerk, I.K., et al., A peptide derived from G0/G1 switch gene 2 acts as noncompetitive inhibitor of adipose triglyceride lipase. J Biol Chem, 2014. 289(47): p. 32559-70. 
126 21. Severson, D.L. and B. Hurley, Inhibition of the hormone-sensitive lipase in adipose

tissue by long-chain fatty acyl coenzyme A. Lipids, 1984. 19(2): p. 134-8.

22. Nagy, H.M., et al., Adipose triglyceride lipase activity is inhibited by long-chain acylcoenzyme A. Biochim Biophys Acta, 2014. 1841(4): p. 588-94.

23. Mayer, N., et al., Development of small-molecule inhibitors targeting adipose triglyceride lipase. Nat Chem Biol, 2013. 9(12): p. 785-7. $112 \mathrm{e} 7$. 


\section{$138 \quad$ Financial Supports}

139 PS received financial support for his $\mathrm{PhD}$ fellowship from the Ministère Français de

140 l'Enseignement Supérieur, de la Recherche et de l'Innovation 